\title{
URBAN EXPANSION MODELING APPROACH BASED ON MULTI-AGENT SYSTEM AND CELLULAR AUTOMATA
}

\author{
Y. N. Zeng ${ }^{1,2 *}$, M. M. Yu ${ }^{1,2}$, S.N. Li $^{3}$ \\ ${ }^{1}$ School of Geosciences and Info-physics, Central South University, Changsha, 410083, China - ynzeng@ csu.edu.cn \\ ${ }^{2}$ Center for Geomatics and Sustainabal Development Research, Central South University, Changsha, 410083, China \\ ${ }^{3}$ Department of Civil Engineering, Ryerson University, Toronto, Ontario Canada M5B 2K3 - (wei1.huang, snli)@ ryerson.ca
}

\section{Commission III, WG III/7}

KEY WORDS: Urban expansion, Modeling, Multi-agent system, Cellular automata

\begin{abstract}
:
Urban expansion is a land-use change process that transforms non-urban land into urban land. This process results in the loss of natural vegetation and increase in impervious surfaces. Urban expansion also alters the hydrologic cycling, atmospheric circulation, and nutrient cycling processes and generates enormous environmental and social impacts. Urban expansion monitoring and modeling are crucial to understanding urban expansion process, mechanism, and its environmental impacts, and predicting urban expansion in future scenarios. Therefore, it is important to study urban expansion monitoring and modeling approaches. We proposed to simulate urban expansion by combining CA and MAS model. The proposed urban expansion model based on MSA and CA was applied to a case study area of Changsha-Zhuzhou-Xiangtan urban agglomeration, China. The results show that this model can capture urban expansion with good adaptability. The Kappa coefficient of the simulation results is 0.75 , which indicated that the combination of MAS and CA offered the better simulation result.
\end{abstract}

\section{INTRODUCTION}

Urban expansion is a land-use change process that transforms non-urban land into urban land (Bai et al., 2012; He et al., 2016). This process results in the loss of natural vegetation and increase in impervious surfaces. Urban expansion alters the hydrologic cycling, atmospheric circulation, and nutrient cycling processes and generated enormous environ-mental and social impacts (Wade et al., 2009; Wu et al., 2014). Therefore, urban expansion modeling is important to understand urban expansion process and mechanism, and predict the urban expansion.

Cellular Automata (CA) model has been increasingly used to simulate urban growth and land use dynamics (Li et al., 2002; He et al., 2006; Ahmed et al. 2018; Li et al. 2017; Maher et al. 2016; Süha et al. 2016). However, there are some limitations because they cannot explicitly consider the influences of social and human factors in urban expansion simulation. Multi-agent systems (MAS) can be defined as a set of agents interacting in a common environment, make land use decisions within the system. Therefore, Multi-agent systems (MAS) model is now used to simulate land use changes (Zhang et al. 2016; Célia et al. 2013; An 2012; Liu et al. 2014). However, this model does not take into account the effect of neighborhood land use on urban expansion. Therefore, coupling CA and MAS model to simulate urban expansion is expected to solve above issues (Ahmed et al. 2017; Tian et al. 2017). The main objective of this paper is to develop an urban expansion model coupling CA and MAS model for simulating spatio-temporal dynamics of urban expansion. The Changsha-Zhuzhou-Xiangtan agglomeration in the middle reaches of the Yangtze River, China was selected as case study to test feasibility, validity and accuracy of the new model.

* Corresponding author 


\section{STUDY AREA AND DATA}

The Changsha-Zhuzhou-Xiangtan agglomeration in the middle reaches of the Yangtze River, China has been experiencing significant growth in both population size and urban area in the last decade. It is important to quantitatively reveal urban expansion in future.

Land use/cover data were excavated using Landsat TM/OLI images from 2006 to 2013. Land use types include construction land, arable land, forest land, water, and other land use. The overall accuracy of classification of land use/cover data reached $80 \%$. We also collected DEM, topographical map, house price map, and socio-economic census data including population density, GDP per capita, urbanization, and total fixed assets.

Using GIS spatial analysis model, we calculated and obtained thematic layers such as, distance to the river, distance to village road, distance to county road, distance to road, distance to highway, distance to bridge, life service, facilitate of work, leisure and entertainment layers.

\section{URBAN EXPANSION MODEL}

\subsection{Model framework}

Based on multi-agents system theory and land use decision-making process, Multi-agent interactive decision-making model (MASM) was developed and supplied

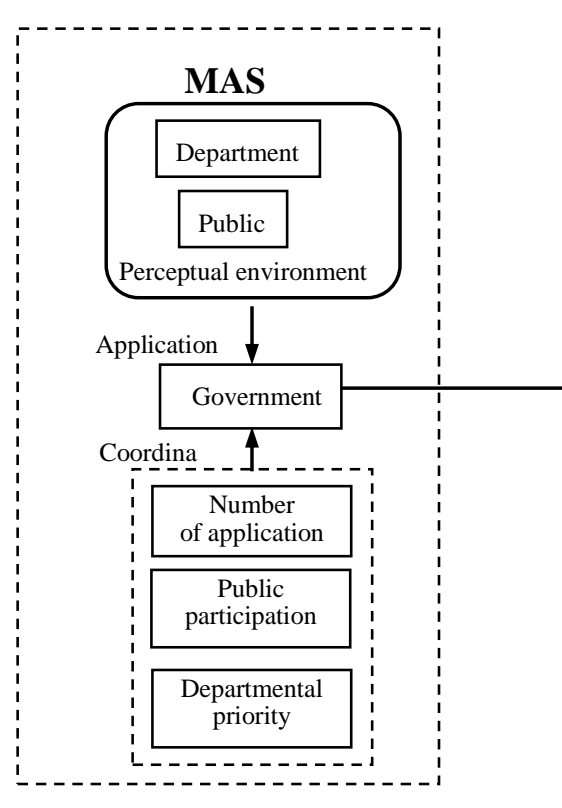

the competition degree of urban land use. CA model use this competition degree of urban land use as urban expansion potential, and take into account neighbourhood influence factors and the conversion intensity of different types of non-urban land into urban land, and simulate the urban expansion.

The urban expansion model based on MAS and CA is depicted with its systematic framework as follows (Fig. 2). MAS and CA are embodied in this spatially explicit model. The MAS determines spatial competition allocations of urban land use through multi-agent based interactive decision-making. CA model determines the space conversion of urban land use and simulates the urban expansion. The model couples human system with the landscape system mainly through spatial competition allocations of urban land use.

\subsection{Multi-agents and their interactive decision making}

MAS includes three categories land use decision-making stakeholders, such as government, departments, and public, which are macro-level decision maker, land administration decision maker and land users, respectively. The MAS determines spatial competition allocations of urban land use through multi-agent based interactive decision-making.

Figure 2. Model framework of MAS and CA 


\subsubsection{Department and public agents and their land use}

\section{decisions}

Department and public agents are pursuing to maximize their own interests. Therefore, based on comprehensive trade-offs of land use effectiveness, department and public agents apply to government for land use. The utility functions of department and public agents for land use are as follows:

$$
U_{i}=\sum_{j=1}^{k} \alpha_{j} X_{j}+\mu_{i j}
$$

$U_{i}$ is the utility of the land use $i$; $X_{j}$ is the decision factor of department and public agents $(\mathrm{j}=1,2,3 \ldots \mathrm{k}) ; \mathrm{a}_{\mathrm{j}}$ is the decision weight; $\mu_{\mathrm{ij}}$ is the random disturbance term.

\subsubsection{Government agent and its land use decisions}

The government agents use competition function to resolve land use conflicts. The competition function is as follows:

$$
C_{t(i, j)}=U_{d(i, j, t)}+\alpha \cdot U_{p(i, j, t)}+P_{t}
$$

$C_{t(i, j)}$ is the competition of land use class $t$ in unit $(i, j) ; U_{d(i, j, t)}$ and $U_{p(i, j, t)}$ are utility functions of land use class $t$ in unit (i,j) for department and public agents, respectively; $\alpha$ is the public agent participation $(0 \leq \alpha \leq 1) ; \mathrm{P}_{\mathrm{t}}$ is priority of department agent to land use class $t \quad\left(p_{t} \geq 0\right)$.

In order to consider the land requirements of department agent and public agent, the government needs to coordinate land use through competition adjustment as follows:

$$
C_{t(i, j)}^{\prime}=C_{t(i, j)}+n_{d} \cdot \delta P_{d}+n_{p} \cdot \delta P_{p}
$$

$\mathrm{C}_{\mathrm{t}(\mathrm{i}, \mathrm{j})}$ is the adjusted competition for land use class $\mathrm{t}$ in unit (i, $\mathrm{j})$; $\mathrm{n}_{\mathrm{d}}$ and $\mathrm{n}_{\mathrm{P}}$ are number of application of department and public agents to the government for the unit $(\mathrm{i}, \mathrm{j}) ; \delta \mathrm{P}_{\mathrm{d}}$ and $\delta \mathrm{P}_{\mathrm{p}}$ is the competition increase of departments and the public agent for each time.

\subsubsection{The degree of urban land use competition}

In multi-agent based interactive decision-making process, the optimal allocation of land use was implemented dynamically based on the degree of competition of all land use types, as well as the sequence of configurations of land use and the constraint condition of land use structure.

\subsection{Cellular automaton model}

CA model determines the space conversion of urban land use and simulates the urban expansion. CA model couples human system with the landscape system mainly through spatial competition allocations of urban land use.

\subsubsection{Cell and its state definitions}

Conventional urban cellular automaton model include urban land, non-urban land cellular states. Taking into account conversion differences of different land uses, we set up five kinds of cellular states: 1) urban-urban land; 2) non-urban land, water; 3) non-urban, arable land; 4) non-urban, forest land; 5) non-urban, unused land. The cellular space is defined in the grid space of $30 \times 30 \mathrm{~m}$ resolution.

\subsubsection{Conversion rules and their probability}

Firstly, the conversion rules are determined for each cellular. Then, according to the state of the cellular and the urban land use policy, the conversion probability is calculated. Rule (1): IF the state of cell at discrete time step (t) is urban land; THEN the state of cell remains as urban land at the next discrete time step $(t+1)$. Rule (2): IF the state of cell at discrete time step $(t)$ is water, THEN the state of cell remains as water at the next discrete time step Rule (3): IF the state of cell at discrete time step $(t)$ is Cultivated land, or forest land, or unused land; THEN the state of cell probably converts as urban land at the next discrete time step $(t+1)$. The probability of cell transition is determined by the comprehensive competitive degree of urban land, the conversion intensity of different land use types, and the influence of neighborhood cell.

$$
P_{V(i, j)}=C_{(i, j)}^{\prime} \times P_{w(i, j)} \times P_{n(i, j)}
$$

In the formula, $P_{v(i, j)}$ is probability of non-urban cellular $(i, j)$ converting to urban land; $\mathrm{C}_{(\mathrm{i}, \mathrm{j})}^{\prime}$ is conversion degree of competition of cellular $(\mathrm{i}, \mathrm{j})$ to urban land; $\mathrm{P}_{\mathrm{w}(\mathrm{i}, \mathrm{j})}$ is land conversion intensity of different land use to urban land; $P_{\mathrm{n}(\mathrm{i}, \mathrm{j})}$ is the influence of neighborhood cellular to center cellular. 


\subsubsection{Conversion intensity}

The different land uses (non-urban land) possess different intensity of conversion from non- urban land to urban land due to their characteristics, location and difficulty of conversion to urban land. In this study, the transfer intensity of different of non-urban land to urban land is calculated.

$$
P_{w}=W_{i}=\frac{\operatorname{Count}\left(L_{i} \rightarrow U|L \rightarrow U|\right)}{\operatorname{Count}(L \rightarrow U)}
$$

$$
(i=1,2,3)
$$

\subsubsection{Influence of neighborhood cell}

The probability that the central cell is influenced by the neighborhood cell is as follows:

$$
\begin{aligned}
& P_{n}=1-\frac{20}{9}(\text { DevelopedRate }-\lambda)^{2} \\
& \text { DevelopedRate }=\frac{\sum_{5 \times 5} \operatorname{con}\left(S_{i, j}=1\right)}{5 \times 5-1}
\end{aligned}
$$

\section{RESULT AND ANALYSIS}

The results of urban land use in 2010 and its changes from 2006 to 2010 simulation using MAS-CA model and were shown in figure 2 . The spatial patterns of simulated urban land use were in accordance with the real pattern in 2010. In terms of spatial distribution of urban land use, it is clear that the simulated spatial patterns based on MAS-CA model effectively represented urban growth in the study area, which matches the trend detected according to the reference maps.

In order to evaluate the accuracy of the simulation, Kappa coefficient was used to examine the degree of match between the simulated and actual urban land use pattern. Kappa coefficient of MAS-CA model was 0.76 . It showed that the combination of MAS and CA offered the better simulation result.

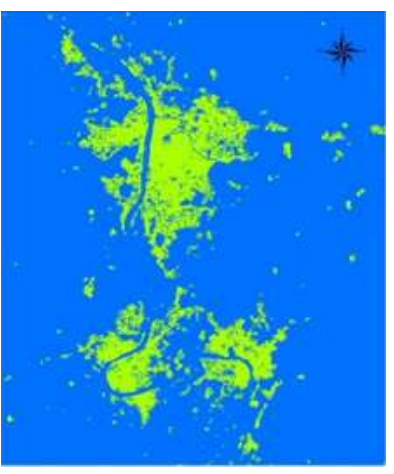

a

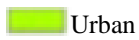

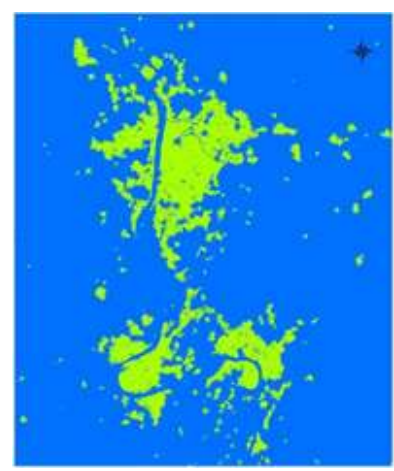

b
Figure 2 urban land use in 2010 (a) real; (b) simulated

\section{CONCLUSION}

Cellular Automata (CA) model has been increasingly used to simulate urban growth and land use dynamics. However, Cellular Automata (CA) model cannot explicitly consider the influences of social and human factors in urban expansion simulation. Multi-agent systems (MAS) are recently developed and applied to simulate urban growth and land use dynamics, which make land use decisions according to social and human agents. However, Multi-agent systems (MAS) do not take into account the effect of neighborhood land use on urban expansion. Therefore, we proposed an urban expansion model coupling CA and MAS model. The case study shows that the proposed urban expansion model based on MSA and CA can capture urban expansion with good adaptability. The Kappa coefficient of the simulation results is 0.75 , which indicated that the combination of MAS and CA offered the better simulation result.

\section{ACKNOWLEDGEMENTS}

This work has been funded by the National Science Foundation of China (No. 41171326, 40771198).

\section{REFERENCE}

Ahmed M., Alison H., Hichem ., Ismaïl ., Jacques T., 2018.

Modelling built-up expansion and densification with

multinomial logistic regression, cellular automata and genetic 
The International Archives of the Photogrammetry, Remote Sensing and Spatial Information Sciences, Volume XLII-3, 2018 ISPRS TC III Mid-term Symposium “Developments, Technologies and Applications in Remote Sensing”, 7-10 May, Beijing, China

algorithm. Computers, Environment and Urban Systems, (67), pp. 147-156.

Ahmed M., Mario C., Ismaïl S., Jacques T., 2017. Coupling agent-based, cellular automata and logistic regression into a hybrid urban expansion model (HUEM). Land Use Policy, (69), pp. $529-540$

An, L., 2012. Modeling human decisions in coupled human and natural systems: Review of agent-based models. Ecol. Modell. (229), pp. 25-36.

Bai, X.M., Chen, J., Shi, P.J., 2012. Landscape urbanization and economic growth in China: positive feedbacks and sustainability dilemmas. Environ. Sci. Technol. 46 (1), pp. 132-139

Célia G. R., Carolina G. A., Cássio G.C. C., Alexandre Z., Ricardo B. M., 2013. A multi-agent model system for land-use change simulation. Environmental Modelling \& Software, (42), pp. $30-46$

He C., Okada N., Zhang Q., Shi P., Li J., 2008. Modelling dynamic urban expansion processes incorporating a potential model with cellular automata. Landscape and Urban Planning, 86(1), pp. 79-91

He, C., Zhang, D., Huang, Q., Zhao, Y., 2016. Assessing the potential impacts of urban expansion on regional carbon storage by linking the LUSD-urban and InVEST models. Environ. Modell. Softw, (75), pp. 44-58.

Liu, J., Axinn, W., 2014. Agent-based modeling in Coupled Human and Natural Systems (CHANS): lessons from a comparative analysis. Ann. Assoc.Am. Geogr, (104), pp. 723 745.

Liu, X., Li, X., Yeh A.G.O., 2006. Multi-agent systems for simulating spatial decision behaviors and land-use dynamics. Science in China Series D: Earth Sciences, 36(11). pp. 1027-1036
Li X., Gong P., Yu L., Hu T., 2017. A segment derived patch-based logistic cellular automata for urban growth modeling with heuristic rules. Computers, Environment and Urban Systems, (65),pp.140-149

Maher M. A., Yuek M. H., Mohammad F. R., Zulfa H. A., 2016. The simulation and prediction of spatio-temporal urban growth trends using cellular automata models: A review. International Journal of Applied Earth Observation and Geoinformation, (52), pp. 380-389

Shikhar D., Akansha S., 2014. Urban sprawl modeling using cellular automata The Egyptian Journal of Remote Sensing and Space Science, 17(2), pp. 179-187

Süha B., Anıl A., Keith C. C. 2016. Cellular automata modeling approaches to forecast urban growth for adana, Turkey: A comparative approach. Landscape and Urban Planning, (153), pp. 11-27

Tian G., Ma B., Xu X., Liu X., Kong L., 2016. Simulation of urban expansion and encroachment using cellular automata and multi-agent system model—A case study of Tianjin metropolitan region, China. Ecological Indicators, (70), pp. $439-450$

Wade, T.G., Wickham, J.D., Zacarelli, N., Riitters, K.H., 2009. A multi-scale method of mapping urban influence. Environ. Modell. Softw. 24 (10), pp.1252-1256.

Wu, J.G., Guo, X.C., Yang, J., Qian, G.X., Niu, J.M., Liang, C.Z., Zhang, Q., Li, A., 2014. What is sustainability science? Chin. J. Appl. Ecol. 25 (1), pp. 1-11.

Zhang H., Zeng Y., Jin X., Shu B., Yang X., 2016. Simulating multi-objective land use optimization allocation using Multi-agent system-A case study in Changsha, China. Ecological Modelling, (320), pp. 334-347 